\title{
Hereditary Transmission of Tetralogy of Fallot, Cardiac Hypertrophy, and Anomalies of Great Vessels in WKY/NCrj Rats
}

\author{
TOSHIRO KURIBAYASHI, MASAFUMI TANIWAKI, KIMIYO NAKAMICHI, \\ TAKASHI NAKAMURA, KAZUTOSHI SHIMOO, MASAO NAKAGAWA, AKINOBU NAGAOKA, \\ TOMOHIKO KOMEDA, AND YASUHIKO IBATA \\ Department of Anatomy [T.Ku., Y.I.], Department of Medicine [M.T., T.N., K.S., M.N.], and Department of \\ Hygiene [K.N.], Kyoto Prefectural University of Medicine, Kyoto, and Takeda Chemical Industries, Ltd.
} [A.N., T.Ko.], Osaka, Japan

\begin{abstract}
We examined 78 fetuses on d 21 of gestation (G21) and 83 neonates on $\mathbf{2} 2$ after birth (A2), which were first generation offspring of WKY rats mated with normal Wistar rats (F1). In addition, we examined six groups of fetuses on d 19 of gestation (G19): 65 Wistar rats, 111 WKY rats, 85 F1, $100 \mathrm{~F} 1 \times$ F1, 92 F1 $\times$ Wistar, and 97 $F 1 \times$ WKY progeny. In the F1 at G19, G21, and $A 2$, there were abnormalities of the pulmonary valve, pulmonary outflow tract, architecture of muscle bundle, and pulmonary arterial branch, as well as hypoplastic ductus arteriosus and postnatal cardiac hypertrophy, similarly in males and females but at a lower incidence and to a lesser extent than in the WKY rats. Severe pulmonary valve dysplasia and ventricular septal defect with overriding of the aorta (tetralogy of Fallot), usually associated with a markedly small ductus, were not present or were very rare in the $\mathrm{F} 1$ and the F1 $\times$ Wistar but were present in the F1 $\times$ WKY and in the F1 $\times$ F1 less prevalently than in the WKY. The size of the ductus showed a continuous distribution in all of the six groups; there was a large skewing toward lower values in the WKY, the F1 $\times$ WKY, and the F1 $\times$ F1. These results suggest that cardiovascular anomalies of WKY rats are transmitted as autosomal recessive or incomplete autosomal dominant traits with an incomplete penetrance and variable expressivity or as polygenic traits. Chromosomal analysis of 31 WKY fetuses revealed no abberations specifically related to the development of cardiovascular malformations. (Pediatr Res 30: 227-231, 1991)
\end{abstract}

\section{Abbreviations}

$P V$, pulmonary valve

PA, pulmonary artery

VSD, ventricular septal defect

F1, first generation hybrids

VFW, ventricular free wall

G, day of gestation

A, day after birth

In epidemiologic studies of congenital heart disease, genetic factors have been strongly suspected on the basis of familial

Received October 25, 1990; accepted May 10, 1991

Correspondence and reprint requests: Toshiro Kuribayashi, M.D., National Institutes of Health, NHLBI, Pathology branch, Bldg. $10 \mathrm{Rm}$ 2N258, Bethesda, MD 20892.

Supported in part by Grant No. 02807096 from the Ministry of Education, Science, and Culture of Japan. occurrence in humans (1-9) and animals (10-19). The aspects of genetic participation are chromosomal aberrations $(1,2,19-$ 22 ), single gene Mendelian inheritance (1, 2, 6-9), or polygenic inheritance in which multiple genes with equal and small effect act additively $(10,11)$. Environmental influences, such as specific teratogenic chemicals and viruses or as yet unidentified and unassessable factors, are also being considered in the etiology of congenital anomalies $(1,23)$. A prevailing hypothesis explains that multifactorial etiology with genetic-environmental interactions, be it linked with polygene or several major genes, is the ultimate cause in a vast majority of cases $(1,2,23-25)$.

We have already described morphologic features of tetralogy of Fallot, PV dysplasia, VSD, abnormal muscle bundle architecture, cardiac hypertrophy, pulmonary hypertension, and anomalies of the great vessels, including hypoplasia of the ductus arteriosus spontaneously occurring in WKY/NCrj rats (15-18). In this study, we carried out mating experiments and chromosomal analysis with the rats. The use of these rats in genetic studies should be particularly beneficial, because the rat strain is an established inbred one maintained under conditions with no specific teratogenic exposure and with minimal variations of other environmental factors.

\section{MATERIALS AND METHODS}

Animals and matings. The WKY rats used for matings were produced by successive selective breeding based on electrocardiographic findings (16) in an air-conditioned room free of specific pathogens. The unrelated Wistar rats with normal cardiovascular systems $(15-18)$ were purchased from Shimizu Jikken Zairyo Inc. (Kyoto, Japan); they were maintained by a random breeding in a closed colony under conventional conditions. Several weeks before matings and throughout pregnant intervals, all of the parents were exposed to the same laboratory environment by being housed, side by side, in suspended wire-bottom cages, with the same laboratory food and sterilized water available ad libitum. Pregnancy was confirmed by identifying sperm in the vaginal smear, and the next day was considered to be the 1 st $d$ of gestation.

First, we mated reciprocally four male WKY rats with four female Wistar rats and two female WKY rats with two male Wistar rats. All of the first litters ( 83 neonates) were sampled at A2, and the second litters ( 78 fetuses) were sampled at G21. The results in these F1 were compared with those from WKY and from Wistar rats at the same stage obtained in the previous study (18). We next examined six groups of fetuses at G19: 63 Wistar rats, $111 \mathrm{WKY}$ rats, $85 \mathrm{~F} 1,100 \mathrm{~F} 1 \times \mathrm{F} 1,92 \mathrm{~F} 1 \times$ Wistar, and $97 \mathrm{~F} 1 \times \mathrm{WKY}$ progeny. The $\mathrm{F} 1 \times \mathrm{F} 1$ progeny were produced 
by sibling mating. Some of the Wistar and WKY rats that were mated with the F1 were not the parents of the F1.

For proper interpretation of the present experimental project and its results, it should be mentioned here that the WKY/NCrj strain of rats is an established inbred one and, therefore all of the rats are presumed to have a homozygous genotype and identical genes including, if any, abnormal ones. In every $F 1$, therefore, all of the alleles including the allele of interest, derived from the WKY gametes of either sex, are considered to be present in heterozygous form and identical in every individual. Similarly, one fourth of the $F 1 \times F 1$ progeny are considered homozygous and half of them are heterozygous for the allele of interest. Furthermore, half of the F1 $\times$ WKY progeny should be homozygous and half of them heterozygous for the allele, and half of the $\mathrm{F} 1 \times$ Wistar progeny should be heterozygous for the allele.

Methods of identifying phenotypes. The hearts, great vessels, and lungs were isolated in the same way as in the previous study (18). We then examined in the same way the cross-sectional area of the ductus arteriosus and the aortic isthmus, the appearance of cardiac valves, VSD, pulmonary outflow tract, architecture of the middle latitudinal muscle bundle, wall thickness/lumen radius ratio of the PA branch, and the width of the ventricular septum, left VFW, and right VFW.

Chromosomal analysis. Thirty-six WKY rat fetuses at G1819 (three litters) and 13 normal Wistar rat fetuses were examined. With the mother rats under urethane anesthesia, the fetuses were rapidly removed from the uterus. The caudal $1 / 3$ of the body was available for chromosomal analysis. The specimen was minced and cultured in RPMI 1640 medium (Nissui Pharmaceutical Co., Ltd., Tokyo, Japan) supplemented with a $15 \%$ FCS for 3-5 d. Cells were treated with colcemid (Hyclone Laboratory Inc., Logan, UT) at a concentration of $0.08 \mu \mathrm{g} / \mathrm{mL}$, then trypsinized, and further treated with $0.075 \mathrm{M} \mathrm{KCl}$ for $15 \mathrm{~min}$ and fixed in methanol-acetic acid solutions with a mixture ratio of $3: 1$. The cells at metaphase were spread by air-drying method and were G-banded with trypsin. They were then arranged according to the scheme and nomenclature for G-bands of rat chromosomes (26). The rostral $2 / 3$ of the body was soon immersed in $10 \%$ formalin for anatomic examination of the cardiovascular system. Hypoplasia of the ductus was estimated qualitatively.

Statistical analysis. The data are expressed as mean \pm SD. Each parameter was judged to be abnormal with reference to the mean \pm 2 SD for the Wistar rats. Because data in males and females were similar in every group, and because various abnormalities occurred in the hybrid groups irrespective of WKY paternity or maternity, the data were analyzed together in every group. The incidence of abnormalities between the groups was compared by the $\chi^{2}$ test.

\section{RESULTS}

$F 1$ at $G 21$ and $A 2$. Severe PV dysplasia occurred only in one of the 78 fetuses and one of the 83 neonates of WKY rats; mild thickening of the PV was present in $27-28 \%$ of the $F 1$ at both stages, and the incidence was significantly lower than in the WKY (Table 1). VSD was present in one of the F1 fetuses. The pulmonary outflow tract was narrow in 35 and $24 \%$ of the F1 at G21 and A2, respectively, about half the incidence in the WKY.

The wall thickness/lumen radius ratio of the PA branch in the F1 was abnormally low in $17 \%$ at G21 and in $15 \%$ at A2, the incidence being similar to that in the WKY; however, the range of the ratio was narrower in the F1 than in the WKY at both stages. The PA branch lesion in the F1 always occurred in the absence of VSD or severe PV dysplasia.

The abnormality of the septal middle latitudinal muscle bundle was present in the F1 fetuses and neonates ( 37 and $34 \%$, respectively) less frequently than in the WKY (81 and $85 \%$, respectively).

The heart wt/body wt of the F1 at A2 was abnormally high in $24 \%$, about half the incidence in the WKY. A very high weight ratio greater than 7.0 was seen in only one of the $F 1$ neonates, whereas it was noted in $16 \%$ of the WKY neonates. The mean ventricular septum/left VFW and right VFW/left VFW in the F1 were intermediate between the Wistar and the WKY at both G21 and A2, as was the incidence of abnormally high individual ratios.

The ductus arteriosus was abnormally small in $21 \%$ of the F1 fetuses, about half as prevalent as in the WKY (47\%). However, the smallest size of the ductus was $28 \mu \mathrm{m}$ in the F1 whereas it was smaller than this in $18 \%$ of the WKY, with the smallest one being $9 \mu \mathrm{m}$, The size of the ductus corrected by the size of the aortic isthmus, the ductus/aorta ratio, was abnormally low in more fetuses than was the uncorrected size in both the WKY (75 versus $47 \%$ ) and the $\mathrm{F} 1$ fetuses (40 versus $21 \%$ ). A double or right aortic arch was present in seven of the 133 WKY but in none of the $161 \mathrm{~F} 1$.

G19 fetuses. Severe PV dysplasia was seen only in the WKY $(14 \%)$, the F1 $\times$ WKY $(6 \%)$, and the F1 $\times$ F1 (3\%), less prevalently in the latter two than in the WKY (Table 2). There was no VSD in the F1 and only one small VSD in the F1 $\times$ Wistar, but in $3 \%$ of the F1 $\times F 1$ and in $11 \%$ of the F1 $\times$ WKY, the incidence in the latter was about one third that in the WKY (35\%).

The abnormality in size of the ductus and the aortic isthmus occurred at G19 to a somewhat lesser extent than at G21 in both the WKY and the F1. The mean and incidence of abnormal values of the ductus and the ductus/aorta ratio decreased in descending order from the WKY rats to the WKY $\times F 1, F 1 \times$ $\mathrm{F} 1$ or $\mathrm{F} 1, \mathrm{~F} 1 \times$ Wistar, and Wistar rats. The distribution of the ductus/aorta ratio was continuous in all six groups (Fig. 1); it was widely ranged because of a large skewing toward lower values in the WKY, the F1 $\times W K Y$, and the F1 $\times$ F1. This pattern was much the same when the ductus size was not corrected by the aorta. Extremely low ductus/aorta ratios $(<1.0)$ were present almost exclusively in the WKY, the F1 $\times$ WKY, and the F1 $\times$ F1 fetuses, the incidence in the latter two ( 8 and $5 \%$, respectively) being significantly lower than in the WKY (21\%); VSD and/or severe PV dysplasia almost always occurred in association with these very small ductus in all of the groups.

Abnormal branching of the PA (18) occurred often in the F1 $\times$ WKY $(29 \%)$ and the WKY fetuses $(52 \%)$, but rarely in the F1 $(8 \%)$, the $\mathrm{F} 1 \times \mathrm{F} 1(10 \%)$, and the $\mathrm{F} 1 \times$ Wistar $(2 \%)$. A double or right aortic arch was present in one of the $F 1$ and one of the $\mathrm{F} 1 \times \mathrm{F} 1$ and in two of the F1 $\times$ WKY. There was a retroesophageal right subclavian artery in one of the F1 $\times$ Wistar. One F $1 \times$ WKY fetus had a common atrioventricular canal in association with a double aortic arch and a small ductus.

Chromosomes. Of the 31 WKY fetuses in which the cell culture was successful, there was a VSD of various sizes in 12 and a mild or severe PV-dysplasia in 14, both occurring together in nine. There were small ductus in 17, double aortic arch in one, and abnormal PA branching in 13. A clonal chromosomal translocation, $\mathrm{t}(1 ; 5)(\mathrm{p} 11 ; \mathrm{q} 13)$, was present in one WKY fetus, in which, however, there was no definite cardiovascular lesion. The remaining $30 \mathrm{WKY}$ and $13 \mathrm{Wistar}$ fetuses had normal karyotypes.

\section{DISCUSSION}

Environmental influences are not likely a major factor for the development of anomalies in the rats described here because all of the parents were housed under the same controlled conditions with very small individual variations. The $F 1$ showed various abnormalities irrespective of maternity, suggesting that either intrauterine environment or cytoplasmic inheritance does not participate in the anomalous development. An independent paternal contribution to the development of tetralogy of Fallot and membranous VSD has been demonstrated in Keeshond dogs and Long-Evans rats $(10,13)$.

In humans, various congenital cardiac malformations occur frequently under the presence of chromosomal anomalies (65- 
Table 1. Data from Wistar and WKY rats and $F 1$ at $G 21$ and $A 2^{*}$

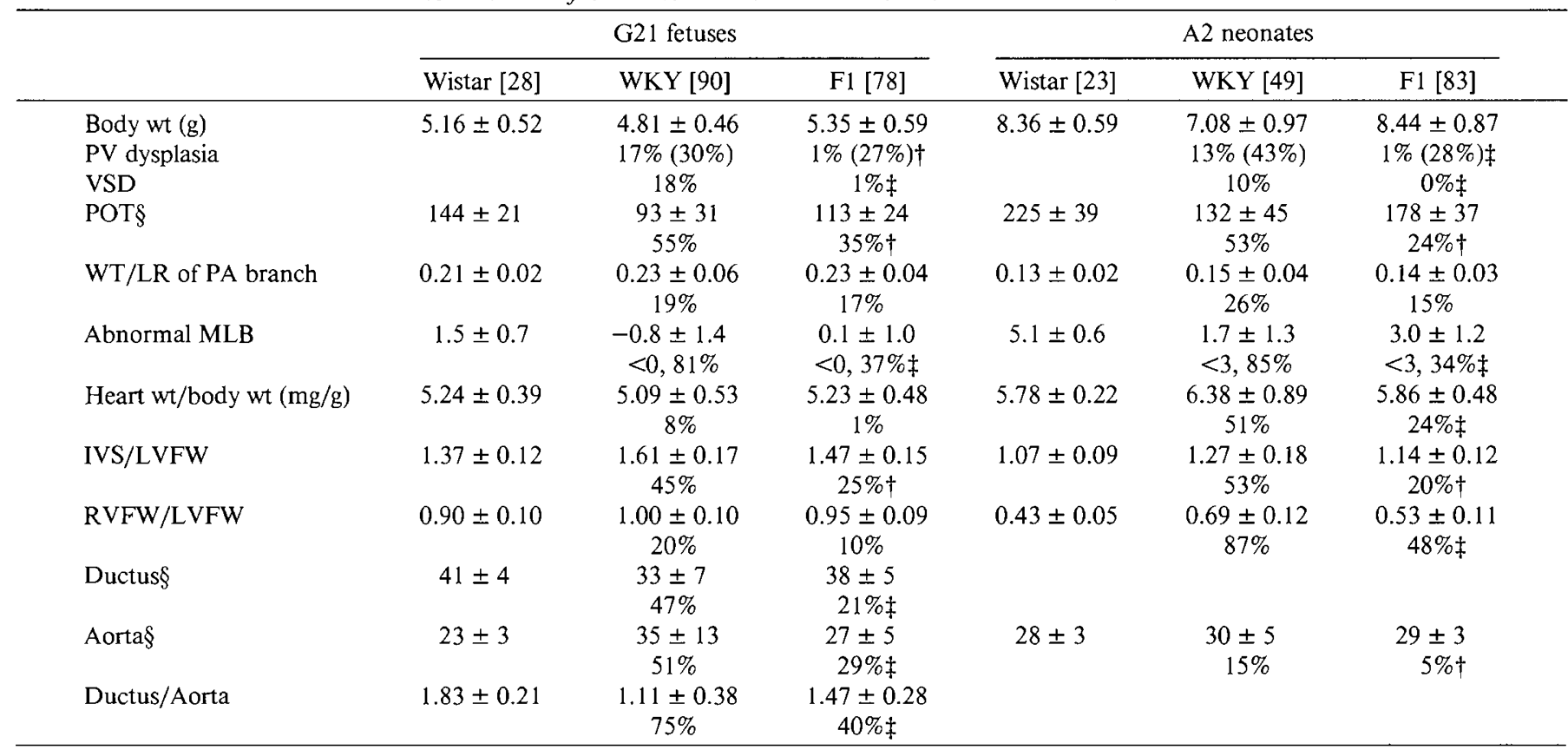

* Data are mean \pm SD. Brackets, number of rats; \%, percentage of rats with abnormalities; POT, pulmonary outflow tract; WT/LR, wall thickness/ lumen radius ratio; MLB, middle latitudinal muscle bundle; IVS, ventricular septum; LVFW, left ventricular free wall; RVFW, right ventricular free wall.

$\dagger p<0.05$; significantly smaller than the percentage in WKY rats.

$\ddagger p<0.01$; significantly smaller than the percentage in WKY rats.

$\S\left(\times 10^{3} \mu \mathrm{m}^{2}\right)$ corrected by $2 / 3$ power of body wt $(\mathrm{g})$.

Table 2. Data in G19 fetuses from various matings*

\begin{tabular}{|c|c|c|c|c|c|c|}
\hline & $\begin{array}{c}\text { Wistar } \\
{[63]} \\
\end{array}$ & $\begin{array}{c}\text { WistarxF1 } \\
{[92]} \\
\end{array}$ & $\begin{array}{c}\mathrm{F} 1 \\
{[85]}\end{array}$ & $\begin{array}{l}\text { F1xF1 } \\
{[100]}\end{array}$ & $\begin{array}{c}\text { F1xWKY } \\
{[97]}\end{array}$ & $\begin{array}{l}\text { WKY } \\
{[111]}\end{array}$ \\
\hline PV dysplasia & $0 \%$ & $0 \%(5 \%)$ & $0 \%(15 \%)$ & $3 \%(16 \%)$ & $6 \%(22 \%)$ & $14 \%(37 \%) \dagger$ \\
\hline VSD & $0 \%$ & $1 \%$ & $0 \%$ & $3 \%$ & $11 \% \dagger$ & $35 \% \dagger$ \\
\hline Ductusł & $48.6 \pm 4.6$ & $\begin{array}{c}45.9 \pm 3.7 \\
5 \%\end{array}$ & $\begin{array}{c}44.4 \pm 4.0 \\
15 \%\end{array}$ & $\begin{array}{c}44.7 \pm 5.4 \\
16 \%\end{array}$ & $\begin{array}{c}43.3 \pm 5.8 \\
22 \%\end{array}$ & $\begin{array}{c}41.2 \pm 7.8 \\
36 \% \S\end{array}$ \\
\hline Aortał & $28.7 \pm 3.4$ & $\begin{array}{c}29.8 \pm 3.7 \\
5 \%\end{array}$ & $\begin{array}{c}31.5 \pm 4.4 \\
19 \% \S\end{array}$ & $\begin{array}{c}31.6 \pm 5.6 \\
18 \%\end{array}$ & $\begin{array}{c}33.1 \pm 5.9 \\
27 \%\end{array}$ & $\begin{array}{c}37.4 \pm 10.6 \\
40 \%\end{array}$ \\
\hline Ductus/Aorta & $1.69 \pm 0.18$ & $\begin{array}{c}1.55 \pm 0.18 \\
12 \% \S\end{array}$ & $\begin{array}{c}1.42 \pm 0.17 \\
26 \% \S\end{array}$ & $\begin{array}{c}1.44 \pm 0.26 \\
30 \%\end{array}$ & $\begin{array}{c}1.34 \pm 0.25 \\
42 \%\end{array}$ & $\begin{array}{c}1.20 \pm 0.37 \\
59 \% \S\end{array}$ \\
\hline Abnormal PA branching & $0 \%$ & $2 \%$ & $8 \%$ & $10 \%$ & $29 \% \dagger$ & $52 \% \dagger$ \\
\hline $\begin{array}{l}\text { Double or right aortic } \\
\text { arch }\end{array}$ & & & 1 & 1 & 2 & \\
\hline Others & & $1 \|$ & & & $1 \pi$ & \\
\hline
\end{tabular}

* Data, mean \pm SD. Brackets, number of rats; \%, percentage of rats with abnormalities; Parentheses, thickening of the cusps with no marked distortion.

\footnotetext{
$+p<0.01$; for comparison with just the left column.

$\ddagger\left(\times 10^{3} \mu \mathrm{m}^{2}\right)$ corrected by $2 / 3$ power of body wt $(\mathrm{g})$.

$\S p<0.05$; for comparison with just the left column.

\| Retroesophageal right subclavian artery.

I Common atrioventricular canal.
}

$99 \%)$, but the association of chromosomal anomalies with cardiac malformations is relatively low $(2-5 \%)(1,2,20-22)$. Our present results suggest that chromosomal abnormality is not related to the development of cardiovascular malformations in WKY rats.

The cardiovascular anomalies in WKY rats did or did not occur in various forms and degrees of severity in the present and previous studies (16-18). This may suggest that there are different alleles of interest, each of which is responsible for each diverse lesion. However, they occurred, isolated or in association, irrespective of the type and severity of abnormalities of parental rats. Therefore, it seems reasonable to explain this phenomenon by referring to the concept "penetrance and expressivity"; once a gene is penetrant, it will frequently exhibit a variable expressivity (27). The concept is thought to be due to two factors: genetic background and environmental influence (27). If so, however, the question still remains as to what determines the unstable expression of various anomalies in WKY rats because the two factors should be most minimal owing to their genetic homogeneity and the identical environment. Also, in an inbred strain of the mouse, various skeletal anomalies occurred independent of the traits of the parental mice $(28,29)$.

Severe PV dysplasia and VSD, being not expressed or rarely expressed in the F1 but being expressed in the WKY, the $F 1 \times$ 

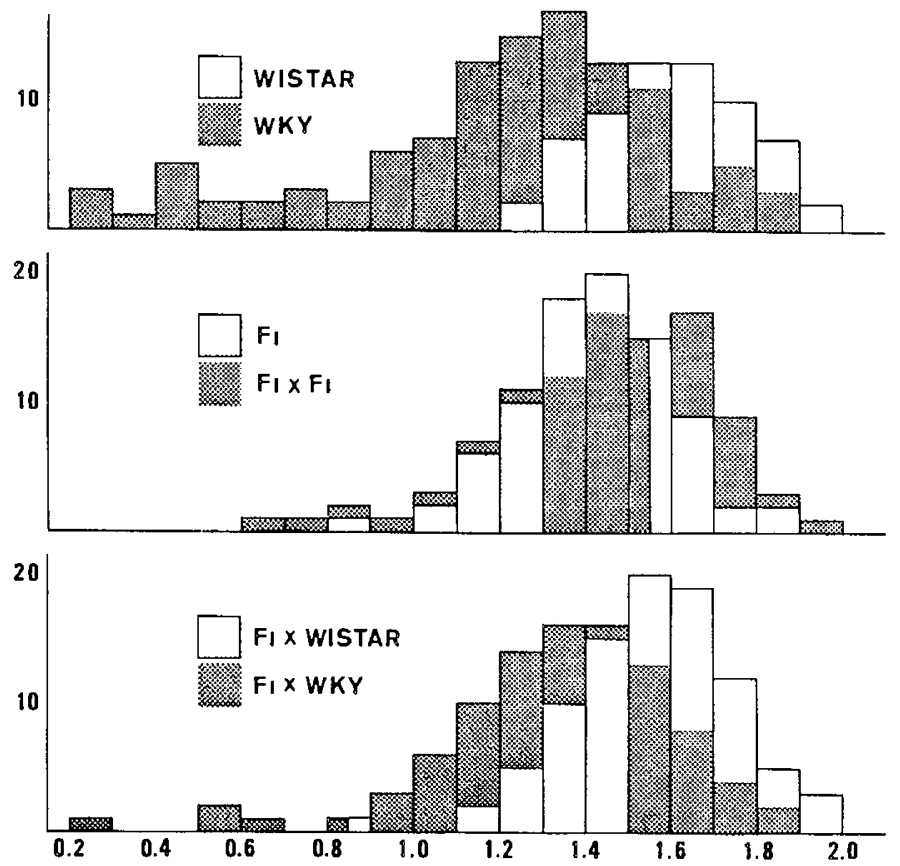

Fig. 1. Histograms showing the distribution of the ductus/aorta ratio of cross-sectional area in various mating groups. Horizontal scale, ductus/ aorta ratio. Vertical scale, number of rats. The distribution in WKY, F1 $\times \mathrm{F} 1$, and $\mathrm{F} 1 \times \mathrm{WKY}$ (dotted columns) is wide because of a marked skewing toward lower values, not depicting a normal curve. The other three groups show almost symmetric normal curves.

WKY, and the $F 1 \times F 1$, are considered to be autosomal recessive traits. The phenotypic expression of other lesions in the F1, including hypoplasia of the ductus, is consistent with autosomal dominant inheritance; in this case also, incomplete penetrance and variable expressivity seem to explain the much lower incidence of the lesions than expected (100\%) from the genotype of the F1. Furthermore, the incidence and severity of most traits were significantly lower in the F1 than in the WKY rats. This difference may be explained by "incomplete dominance"; the presence of an allele in a heterozygote does not necessarily define the phenotype, depending on the nature of the allele at the paired locus (27). This phenomenon is also seen in other congenital anomalies (28-30).

In our previous study (18), we suggested that various cardiovascular lesions could occur secondarily to the hemodynamic effects exerted by an increase in flow impedance through a hypoplastic ductus. A heart lesion that apparently bears no developmental relationship to another cardiac defect may be a manifestation of a common mechanism of maldevelopment due to a core lesion (2). This idea leads us to the assumption that a threshold for each abnormality is present along a continuous scale of the ductus size and the threshold, each varying according to the corresponding lesion. Thus, the threshold for a lesion with low incidence such as VSD or severe PV dysplasia should be high.

The expression of a trait that is characterized by a quantifiability and a continuous distribution of values with a normal curve, such as length or color, is explained by polygenic inheritance; the greater the accumulation of the genes, the greater becomes the expression of the trait $(10,11,31)$. This theory may also explain the continuous distribution of the ductus size in the WKY rats. There are, however, some difficulties. The distribution of the ductus size ranged most widely in the WKY although the genes of interest are considered to have the greatest accumulation and homogeneity in the WKY rats. When highly inbred lines continue to exhibit variation in a polygenic trait, the variation is attributed to environmental rather than genetic causes (31). Thus, the widest distribution of the ductus size in the WKY should imply that hypoplasia of the ductus cannot be explained simply as a polygenic trait. A similar distribution of various skeletal anomalies in an inbred mouse strain has been explained by multifactorial inheritance with environmental influences $(28,29)$.

The present results are not fully concordant with either single gene Mendelian inheritance or polygenic inheritance, as far as the known traits are concerned, without the invoking of a strong participation of highly variable environmental influences. It has been stated in the theory of multifactorial inheritance that a major maldevelopment can be produced by a minor environmental stimulus in the early stage of development $(1,2,23,24)$, although we have no clue as to its identification at present. Furthermore, we know little yet about the cardinal defect that, as the primary expression of the genetic defect, underlies the various traits. Even hypoplasia of the ductus must be an expression of remote gene effects rather than the primary one $(29,32)$. The genetic and environmental problems in the WKY rats thus should be left open until the underlying biochemical process or the presence of causal molecular defects is ultimately ascertained (32).

Acknowledgments. The authors thank Prof. Kohei Shiota, Kyoto University, and Dr. Sen-ichi Oda, Nagoya University, for giving kind suggestions; Dr. Alice Cary, Kyoto Baptist Hospital, for correction of the English text; and Masayoshi Kitagawa, Takeda Chemical Industries Ltd., for raising the rats.

\section{REFERENCES}

1. Nora JJ 1989 Etiologic aspects of heart diseases. In: Adams FH, Emmanouilides GC, Riemenschneider TA (eds) Heart Disease in Infants, Children, and Adolescents. Williams \& Wilkins, Baltimore, pp 15-23

2. Nora JJ, Nora AH 1984 The genetic contribution to congenital heart diseases. In: Nora JJ, Takao A (eds) Congenital Heart Disease. Causes and Processes. Futura Publishing Co, New York, pp 3-13

3. Campbell M, Goodwin J 1965 Some factors in the etiology of ventricular septal defect. Prog Cardiovasc Dis 7:417-433

4. Fraser FC, Hunter ADW 1975 Etiologic relations among categories of congenital heart malformations. Am J Cardiol 36:793-796

5. Cascos AS 1971 Genetics of Fallot's tetralogy. Br Heart J 33:899-904

6. Ferencz C, Boughman JA, Neill CA, Brenner JI, Perry LW 1989 Congenita cardiovascular malformations: questions on inheritance. J Am Coll Cardio 14:756-763

7. Maron BJ, NichoIs III PF, Pickle LW, Wesley YE, Mulvihill JJ 1984 Pattern of inheritance in hypertrophic cardiomyopathy: assessment by M-mode and two-dimensional echocardiography. Am J Cardiol 53:1087-1094

8. ten Cate FJ, Hugenholtz PG, Van Dorp WG, Roelandt J 1979 Prevalence of diagnostic abnormalities in patients with genetically transmitted asymmetric septal hypertrophy. Am J Cardiol 43:731-737

9. Clark CE, Henry WL, Epstein SE 1973 Familial prevalence and genetic transmission of idiopathic hypertrophic subaortic stenosis. N Engl J Med 289:709-713

10. Patterson DF, Pyle RL, Van Mierop L, Melvin J, Olson M 1974 Hereditary defects of the conotruncal septum in Keeshond dogs: pathologic and genetic studies. Am J Cardiol 34:187-205

11. Patterson DF, Pyle RL, Buchanan JW, Trautvetter E, Abt DA 1971 Hereditary patent ductus arteriosus and its sequelae in the dog. Circ Res 29:1-13

12. Patterson DF, Haskins M, Schnarr WR 1981 Hereditary dysplasia of the pulmonary valve in beagle dogs. Am J Cardiol 47:631-641

13. Fox MH 1967 Genetic transmission of congenital membranous ventricular septal defects in selectively inbred substrains of rats. Circ Res 20:422-433

14. Detweiler DK 1964 Genetic aspects of cardiovascular diseases in animals. Circulation 30:114-127

15. Kuribayashi T 1987 Spontaneously occurring hypertrophic cardiomyopathy in the rat. I. Pathologic features. Jpn Circ J 51:573-588

16. Kuribayashi T, Mizuta T, Shimoo K, Kubota Y, Katsume H, Nakagawa M, Ibata Y 1988 Spontaneously occurring hypertrophic cardiomyopathy in the rat. II. Distribution of, and correlations between, various cardiac abnormal ities in the WKY/NCrj and its related strains. Jpn Circ J 52:1156-1170

17. Kuribayashi T, Shimoo K, Nakamura T, Taniwaki M, Hamaoka K, Nakagawa M, Ibata Y, Komeda T, Nagaoka A 1990 Tetralogy of Fallot, pulmonary valve stenosis, ventricular septal defect, and hypertrophic cardiomyopathy in WKY/NCrj rats. Pediatr Res 27:483-487

18. Kuribayashi T, Shimoo K, Nakamura T, Hamaoka K, Nakagawa M, Ibata Y, Mizuta T, Komeda T, Nagaoka A 1990 Tetralogy of Fallot, cardiac hypertrophy, pulmonary hypertension, and anomalies of great vessels in fetuses and neonates of WKY/NCrj rats. Pediatr Res 28:429-436

19. Pexieder T, Miyabara S, Gropp A 1981 Congenital heart disease in experimental (fetal) mouse trisomies: incidence. In: Pexieder T (eds) Mechanisms of 
Cardiac Morphogenesis and Teratogenesis. Raven Press, New York, pp 389399

20. Van Praagh S, Truman T, Firpo A, Bano-Rodrigo A, Fried R, Mcmanus B, Engle MA, Van Praagh R 1989 Cardiac malformation in trisomy-18: a study of 41 postmortem cases. J Am Coll Cardiol 13:1586-1597

21. Matsuoka R, Misugi K, Goto A, Gilbert EF, Ando M 1983 Congenital heart anomalies in the trisomy 18 syndrome, with reference to congenital polyvalvular disease. Am J Med Genet 14:657-668

22. Emerit I, De Grouchy J, Vernant P, Corone P 1967 Chromosomal abnormalities and congenital heart disease. Circulation 36:886-929

23. Nora JJ, Nora AH 1984 The environmental contribution to congenital heart diseases. In: Nora JJ, Takao A (eds) Congenital Heart Disease. Causes and Processes. Futura Publishing Co, New York, pp 15-27

24. Nora JJ 1968 Multifactorial inheritance hypothesis for the etiology of congenital heart diseases. The genetic-environmental interaction. Circulation 38:604-617

25. Fraser FC 1976 The multifactorial/threshold concept-uses and misuses. Teratology 14:267-280
26. Sasaki M, Kodama Y, Hayata I, Yoshida MC 1979 Chromosome markers in 12 inbred strains of the norway rats. Rattus norvegicus. Cytogenet Cell Genet 23:231-240

27. Goodenough U 1987 Related genes: alleles, isoloci, and gene families. In: Genetics, 3rd Ed. Everbest Printing Co, Ltd, Hong Kong, pp 591-617

28. Gruenberg H 1951 The genetics of tooth defect in the mouse. Proc R Soc Lond [Biol] 138:437-451

29. Gruenberg H 1952 Genetical studies in the skeleton of the mouse. IV. Quasicontinuous variations. J Genet 51:95-114

30. Haverkamp Begemann N, Van Lookeren Campagne A 1952 Homozygous form of Pelger-Huet's nuclear anomaly in man. Acta Haematol (Basel) 7:295-303

31. Goodenough U 1987 Genes that cooperate to produce complex phenotypes and quantitative traits. In: Genetics, 3rd Ed. Everbest Printing Co Ltd, Hong Kong, pp 642-680

32. Lalouel JM 1987 Common disease: from phenotype to genotype. In: Vogel F Sperling K (eds) Human Genetics. Proceedings of the 7 th International Congress Berlin 1986. Springer-Verlag, Berlin, pp 294-301

\section{Announcement}

\section{Society for Adolescent Medicine Annual Meeting}

The Society for Adolescent Medicine will hold its annual meeting from March 19 to March 22, 1992 in Washington, DC at the Omni Shoreham Hotel. The theme for this meeting will be "Adolescent Health Policy and Advocacy." In addition to addressing this topic, the Society will present new material on a broad range of issues important to adolescent physical and emotional health, including AIDS, teenage sexuality and pregnancy, eating disorders, depression, and risk-taking behaviors such as drug and alcohol use. Meeting presentations include all-day workshops, 3-hour clinically oriented workshops, research networking breakfasts and luncheon seminars, scientific research paper presentations, and poster sessions, as well as the prestigious Gallagher Lecture Series. CME/CEUs are available. For additional information, contact: the Society for Adolescent Medicine, Suite 120, 19401 E. U.S. Highway 40, Independence, MO 64055 or call (816) 795-8336. 